\title{
UM NOVO NOME E DUAS NOVAS COMBINAÇÕES NA TRIBO GNAPHALIEAE (ASTERACEAE) ${ }^{1}$
}

\author{
LEONARDO PAZ DEBLE ${ }^{2}$
}

\section{RESUMO}

Um novo nome - Gamochaeta chilensis Deble - é atribuído a Gamochaeta foliosa (Phil.) Anderberg, por ser este ilegítimo. Duas novas combinações são propostas: Gamochaeta grazielae (Rizzini) Deble, para Gnaphalium grazielae Rizzini, e Pseudognaphalium cabrerae (S. E. Freire) Deble, para Gnaphalium cabrerae S. E. Freire.

Palavras-chave: Gamochaeta, Gnaphalium, Pseudognaphalium, novo nome, novas combinações.

\section{ABSTRACT}

A new name - Gamochaeta chilensis Deble - is created to Gamochaeta foliosa (Phil.) Anderberg, because it is illegitimate. Two new combinations are proposed: Gamochaeta grazielae (Rizzini) Deble, to Gnaphalium grazielae Rizzini, and Pseudognaphalium cabrerae (S. E. Freire) Deble, to Gnaphalium cabrerae S. E. Freire.

Key Words: Gamochaeta, Gnaphalium, Pseudognaphalium, new name, new combinations.

\section{INTRODUÇÃO}

$\mathrm{Na}$ revisão da tribo Gnaphalieae para o Brasil, constatou-se que Gamochaeta foliosa (Phil.) A. Anderb., por ser combinação ilegítima, requer a designação de um novo nome, e que duas espécies de Gnaphalium necessitam transferência: Gnaphalium grazielae Rizzini, para o gênero Gamochaeta Weddel, e Gnaphalium cabrerae S. E. Freire para Pseudognaphalium Kirpichnikov.

\section{NOME NOVO}

\section{Gamochaeta chilensis Deble, nom. nov.}

Basiônimo: Gnaphalium foliosum Phil., Linnaea 3, p. 163, 1864-1865 [nom. illeg.] (non Gnaphalium foliosum Poiret, Encyclopedie Methodique Botanique, Supplement II, p. 384, 1812).

TIPO-CHILE, Prov. Colchagua, Llico, sine data, Landbeck, sine numero. Holotypus SGO n. v., Isotypus LP!

= Gamochaeta foliosa (Phil.) A. Anderb., Opera Bot., n. 104, p. 157, 1991. [Comb. Illeg.]

O binômio Gamochaeta foliosa resulta de uma combinação feita por Anderberg (1991), com base em Gnaphalium foliosum, espécie descrita por Philippi, em 1865. O binômio Gnaphalium foliosum, todavia, foi utilizado anteriormente por Poiret (1812), na Encyclopedie Methodique Botanique (Supplement II), o que torna ilegítima a proposição de Philippi pelas regras de nomenclatura botânica. A combinação feita por Anderberg (1991), por conseguinte, é também ilegítima, exigindo um novo nome para esta espécie chilena de Gamochaeta.

\section{NOVA COMBINAÇÃO}

Gamochaeta grazielae (Rizzini) Deble, comb. nov.

Basiônimo: Gnaphalium grazielae Rizzini, Revista Bras. Biol. 7, p. 278, 1947.

TIPO - BRASIL, Estado do Rio de Janeiro, S. Conrado (Gávea), C. Rizzini, 16.VIII.1946. holotypus RB 57.771.

A recente revisão das espécies brasileiras de Gamochaeta Weddel (Deble \& Marchiori, in prep.), permitiu constatar que Gnaphalium grazielae Rizzini deve ser transferido a esse gênero. Gamochaeta grazielae relaciona-se a

\footnotetext{
Artigo recebido em 05/01/2006 e aceito para publicação 27/01/2006.

2 Biólogo, Msc., Bolsista CAPES, doutorando do Programa de Pós-Graduação em Engenharia Florestal, Centro de Ciências Rurais, Universidade Federal de Santa Maria, CEP 97105-900, Santa Maria (RS). Deble.biol@bol.com.br
} 
Gamochaeta pensylvanica (Willd.) Cabrera; suas brácteas involucrais, todavia, são agudas no ápice. Pelo porte e tipo de inflorescência, a espécie também se aproxima de Gamochaeta platensis (Cabrera) Cabrera, diferindo, contudo, pela ausência de pêlos glandulares na face adaxial das folhas, que não são marcadamente discolores.

\section{Pseudognaphalium cabrerae (S. E. Freire) Deble, comb. nov.}

Basiônimo: Gnaphalium cabrerae S. E. Freire, Cat. P. Vasc. Rep. Arg. 2 (Monogr. Syst. Bot. Missouri Bot. Gard. 74 , p. $1.245,1999)$.

$=$ Gnaphalium philippii Cabrera, Revista Mus. La Plata, Secc. Bot. 4, p. 164, 1941 [nom. nov. illeg.] (non Gnaphalium philippi Gand., Bull. Soc. Bot. France 65, p. 42, 1918);

$=$ Gnaphalium fastigiatum Phil., Anales Univ. Chile 90, p. 15, 1895 [nom. Illeg.] (non Thunb., Prodr. Pl. Cap. 148, 1800 ).

O gênero Pseudognaphalium Kirp. encerra cerca de 95 binômios válidos, com distribuição predominantemente americana, ocorrendo dezoito ou dezenove espécies, somente na Argentina.

Tanto na "Flora Fanerogámica Argentina" como no "Catálogo de las Plantas Vasculares de la República Argentina", Freire $(1995,1999)$ não reconhece como distintos os gêneros Gnaphalium L. e Pseudognaphalium Kirp. Pseudognaphalium, todavia, separa-se de Gnaphalium, por apresentar brácteas involucrais monocromáticas com estereoma dividido, pelo pápus monomórfico (igual nas flores femininas e hermafroditas), bem como pela coloração amarela, branco-esverdeada ou branco-rosada, das flores. Em verdade, Pseudognaphalium aproxima-se mais de Achyrocline (Less.) DC. do que de qualquer outro gênero, posto que ambos separam-se unicamente pela forma dos pêlos "twin-hairs" dos aquênios e pelo número de flores nos capítulos. Uma vez reconhecido o gênero Pseudognaphalium, surge a necessidade de transfererir Gnaphalium cabrerae S. E. Freire para o gênero de Kirpichnikov.

Pseudognaphalium cabrerae é espécie relacionada a Pseudognaphalium cheiranthifolium (Lam.) Hilliard \& Burtt, da qual separa-se pelo menor tamanho dos capítulos, bem como pelas brácteas involucrais obtusas. De Pseudognaphalium tarapacanum (Phil.) A. Anderb., difere pelo maior porte, pelos talos eretos e pela forma das folhas.

\section{AGRADECIMENTOS}

A Norma Deginani (SI), pelo acesso ao material de Pseudognaphalium cabrerae e aos fotótipos do Instituto Darwinion. A Laura Tharlegui e a Susana Freire (LP), pela consulta aos tipos e fotótipos do Herbário do Museu de La Plata.

\section{BIBLIOGRAFIA}

Anderberg, A. Taxonomy and phylogeny of the tribe Gnaphalieae (Asteraceae). Opera Bot., Copenhagen, n. 104, p. 1-195, 1991.

Cabrera, A. L. Observaciones sobre las InuleaeGnaphalineae (Compositae) de América del Sur. Bol. Soc. Argentina Botanica, La Plata, v. 9, p. 362-383, 1961

Freire, S. E. Asteraceae. Tribu IV. Inuleae. Flora Fanerogámica Argentina. Córdoba, n. 14, p. 1-60, 1995.

Freire, S. E., Iharlegui, L., Sinopsis preliminar del género Gamochaeta (Asteraceae, Gnaphalieae). Bol. Soc. Argentina Botanica, La Plata, v. 33, n. 1-2, p. 23-35, 1997.

Merxmüller, H., Leins, P., Roessler, H. Inuleae systematic review. The biology and chemistry of the Compositae (ed. V. H. Heywood, J. B. Harbone, B. L. Turner). London, p. 577-602, 1977.

Poiret, J. L. M. Encyclopedie Methodique Botanique. Suppl. II, Paris, p. 384, 1812.

Rizzini, C. T. Novitates Rubiacearum Compositarumque. Revista Bras. Biol., Rio de Janeiro, n. 7, p. 278-280, 1947. 